\title{
Modelling ANd Simulation Of Sustainable Systems: An Engineering Design Course Project
}

\author{
Flavio Firmani $^{1}$ and Kevin Oldknow ${ }^{2}$ \\ ${ }^{1}$ School of Mechatronic Systems Engineering, Simon Fraser University, Surrey, Canada \\ ${ }^{2}$ School of Sustainable Energy Engineering, Simon Fraser University, Surrey, Canada \\ Corresponding Author: ffirmani@sfu.ca
}

\begin{abstract}
To enhance the learning objectives of the course: Systems Modelling and Simulation (MSE 380), a Design-Based Learning (DBL) project centered on sustainability was developed and has been implemented for five years. The project consists of designing, modeling, and simulating a renewable energy system that solves a particular problem within a predefined scenario. The scenario changes every year: past scenarios are a remote dwelling, a camping trip, a daily-life setting, a village in an underdeveloped country, and the design of a device that assists in the fight against COVID-19. The design of the system comprises two phases; first renewable energy is harvested and stored, and later the stored energy is used to solve the problem. Students model the systems using statespace representation and linear graphs; and simulate the response as linear, linearized, and nonlinear problems. Project examples for the scenario of underdeveloped villages are: discharge of flooded rice fields during monsoon season in South Asia using pumps, irrigation during the drought season in Northern India using stupas (artificial glaciers), uncovering of a Russian village after sandstorm with mechanical shovels, irrigation in SubSaharan Africa using solar uplift towers, saving crops from freezing temperatures in rural Iran using solar collectors (as opposed to burning tires which is the current practice), and producing hydroelectricity to power a cooking device in an Amazonian village. Our pedagogical experience with this didactic approach has been very positive. Students are creative and engaged with their own designs. As the project description and requirements have evolved through the years, not only the quality of the projects has improved but also it has had a positive impact on the course learning.
\end{abstract}

Keywords: Sustainability system, design-based learning, modelling, simulation, engineering design.

\section{INTRODUCTION}

Systems Modelling and Simulation (MSE 380) is a $3^{\text {rd }}$ year core course in the School of Mechatronic Systems Engineering at Simon Fraser University. This course covers fundamental concepts of modelling based on state- space representation, transfer functions, and linear graphs of mechanical, electrical, fluid, thermal, and hybrid systems [1]. Likewise, the course introduces simulation software tools that allow students to analyze the response of linear, linearized, and nonlinear models.

To promote and solidify the learning objectives, a Design-Based Learning (DBL) project centered on sustainability was developed and has been implemented for five years. DBL is a form of Problem-Based Learning (PBL), where students actively learn by exploring real-life problems. Additional pedagogical components can be attributed to DBL, as it not only requires the students to manage their time and resources but also incorporates a central deliverable of designing an artefact, system, or solution [2]. The emphasis of PBL is characterized by the self-directed learning process of teams while developing problem-solving skills and learning to transfer knowledge to new situations [3]. PBL is a pedagogical strategy in which students solve context specific cases and openended challenging problems [4]. Studies on PBL have shown that the motivation of students for learning increases because students perceive PBL to be more enjoyable and challenging [5]. PBL also promotes cognitive engagement as students become more active in the use of information sources and libraries [5]. Studies also suggest that this pedagogical approach increases long-term retention of course material [6]. One negative aspect of PBL is that since students dedicate more time than in traditional education, it can produce an increase of stress [7]. In general, engineering curricula incorporate design projects in courses that are dedicated to engineering design, e.g., cornerstone or capstone courses. However, courses that are considered primarily engineering science can benefit significantly from the introduction of design projects that focus on the material of the course [8].

This paper aims to present the implementation of a DBL project in MSE 380 and the experience gained by students and instructors. The reminder of the paper is structured as follows: A description of the course project and its requirements, project management, examples of student projects, pedagogical experience, and conclusions. 


\section{COURSE PROJECT}

\subsection{Project Description}

Over the years the requirements of the project have evolved, however the base of the project have remained the same. The project requirements include:

Project Statement: Design, Model, and Simulate a Sustainable Energy System that Collects, Stores and Consumes Energy to Solve a Problem in a (the statement incorporates a scenario).

Project Scenarios: Every year the scenario changes. In doing so, the students do not have the option to either copy or be influenced by projects from previous years. Scenarios from the past five years have included:

Remote Dwelling (2015). Assume a cabin isolated in a remote location in Canada, where there are no power lines or a gas/diesel generator. Identify a particular problem in the dwelling, e.g., comfort or functionality. Canada is a large territory with different ecosystems: forests, wetlands, grasslands, tundra, lakes, rivers, and coastal and marine areas.

Camping Trip (2017). Consider a camping trip in a real place in British Columbia. There are diverse places such as lakes, mountains, ocean, rivers, and even deserts. Remote camping involves a certain degree of sacrifice, no cars, power grid, toilets, warm baths, etc. Identify a problem that you may encounter in a camping trip. You may use a natural source of energy or energy dissipated from an outdoor activity.

Daily-Life Setting (2018). Identify a problem from a daily-life setting that, if solved, would have a socioeconomic impact, such as improving the quality of life of an individual, environmental benefit, saving money, etc. You may use a natural source of energy or energy dissipated or wasted from an external source.

Village from Developing Country (2019): Historically, engineering has been a main contributor for increase in life expectancy, improvement of health conditions, and increase in mobility and productivity, among others. Advancements in technologies have made possible to develop efficient systems of transportation, housing and shelter, agricultural production, sanitation and waste management, essential medical devices, medical care, etc. However, in remote areas of developing countries, there are undeveloped villages, where even the most basic needs are not present. Identify a particular or distinctive problem from an undeveloped village, preferably a place that you are familiar.

COVID-19 Infected Location (2020): Design a device that will assist in the fight against COVID-19. Identify a problem related to COVID-19 of a particular community (anywhere in the world) that requires a solution. The topic is not limited to essential medical equipment, such as ventilators, sterilizers, disinfectant devices, and air purifiers. It can be a system that assists to maintain social distancing, or helps families who live with an infected patient, etc. Use a renewable energy source from the particular community or harvest unused energy from an existing system (energy dissipated by humans, machines, etc.) to power the system.

\subsection{Project Requirements}

There are four main components in this project: Design of Sustainable System, Modelling, Simulation, and Design Reflection.

2.2.1. Design of Sustainable System. Students must design a sustainable system that will solve a particular problem within the scenario. Doing so requires the following.

Problem Definition: Identify a problem in the scenario and determine the source of energy that will power the system (multiple sources of energy are permitted). Identify a set of design criteria and a set of design constraints that are required for the system.

System Design Requirements: Complete a functional decomposition of the system into three subsystems, as follows. Energy Collection: establish the source of energy (this will become the input variable of the system). Investigate realistic statistical data regarding the selected source of energy, whether it is from a natural resource, i.e., wind power, solar radiation, precipitation, etc., using official statistical tables, or from an external dissipating energy source. Energy Storage: design a subsystem that will store energy, this can be used to fully power the system, or as a complementary source of energy when required. Some examples of energy storage are potential energy, kinetic energy, electrical potential, temperature differences, pressure, etc., the only exception is chemical storage, i.e., batteries. Energy Consumption: employ the stored energy to power the system that will solve the problem that the team identified.

Design Originality and Complexity: Design originality will be assessed. There is a large variety of potential needs or applications. Also think about different methods for extracting, storing, and consuming energy. Students will also be evaluated based on the complexity of their design.

Alternative Concepts: It is important for the teams to explore different problems or solutions. Students may either investigate different problems within a particular scenario (inquiry-based problem) or different solutions for a particular identified problem (design conceptualization). Present at least three valid and distinctive concepts 
(including the final concept) that can be implemented. If the concepts share the same energy source, then the problem to be solved or the subsystems that solve the problem must be different. Include simple sketches of these concepts.

Design Selection: Justify why and how you chose a particular concept. Describe the overall system, the subsystems and all the components interacting with one another (use of graphs and schematic diagrams are highly recommended).

2.2.2. Modelling: This is the core of the project. Students model their systems using state-space representation and linear graphs [1]. Teams develop two models: energy storage and energy consumption. This involves:

Data Collection (inputs): Introduce the location and conditions of the place the system is designed for. This data may be ambient temperature, precipitation, water flow, etc. Cite the reference where this data was found (preferably official tables) and the sampling frequency. Since the data will likely be presented as discrete values, teams will be required to interpolate these data to be able to simulate the models at any instant. Plot these inputs before simulating the model.

Element Modelling: The overall systems will be modelled as a sequence of elements that are connected either in series or in parallel. In general, real systems have a large number of physical elements. Identify the most critical elements for the model. Although there is no limitation on the number of elements, it is expected to have around 12 elements for the whole system. The selection and interconnection of these elements will determine how close the model is in relation to a real system. Note there are no budget restrictions, e.g., there is nothing that constrains you to have solar panels, flywheels, or underground thermal capacitors. Each element will be modelled with a constitutive equation, a first order differential equation based on the across and through variable analogies [1]. Write the constitutive equations in a parametric form. Initially, teams will consider linear elements, but later in the project, teams will replace one or two linear elements with nonlinear elements.

Design Parameters: The parameters of each element, for example stiffness of a spring, moment of inertia of a flywheel, coefficient of convection of air, among others, must be introduced in a table that includes symbol, definition, and realistic value. Values for all physical properties used in the model should be written according to reliable engineering sources, and the references should be clearly cited in the report. Note, during the simulation the response of the system will depend on these quantities. Students will recognize the effect of changing these parameters on the response of the systems and modify accordingly to provide a better performance.
System Modelling: Develop the models for the storage and consumption subsystems. Establish continuity and compatibility relations that will permit the interconnection of elements [1]. Combine the equations in a clear, organized, and systematic manner to reach the final set of state and output equations, which will generally be in the following form when nonlinear terms are included:

$$
\begin{aligned}
& \dot{\boldsymbol{q}}=f(\boldsymbol{q}, \boldsymbol{r}) \\
& \boldsymbol{y}=h(\boldsymbol{q}, \boldsymbol{r})
\end{aligned}
$$

Here $\boldsymbol{q}$ is the state vector, $\boldsymbol{r}$ is the input vector, and $\boldsymbol{y}$ is the output vector. The functions $f$ and $h$ are the state and output equations for the system, respectively. While eq. (1) can be used directly for nonlinear model simulation, the following simplified, matrix-based form is used for the purposes of simulating linear and linearized models:

$$
\begin{aligned}
& \dot{x}=\mathrm{A} x+\mathrm{B} u \\
& y=\mathrm{C} x+\mathrm{D} u
\end{aligned}
$$

where $\boldsymbol{x}$ is the state vector, $\mathbf{A}$ is the system matrix, $\boldsymbol{u}$ is the input vector, $\mathbf{B}$ is the input distribution matrix, $\mathbf{C}$ is the output gain matrix, and $\mathbf{D}$ is the feed forward gain matrix.

Linear Graphs: Identify the single and two-port elements, as well as the source elements. Develop and sketch the linear graph representation of the system. Establish the state-space shell equations (energy storage elements), continuity and compatibility relations, and other equations (energy dissipating elements and two-port elements). Develop the state-space representation in the form given in eq. (2), or eq. (1) if there are any nonlinear terms to include.

2.2.3. Simulation: Students employ numerical algorithms to evaluate the differential equations that were derived from system modelling

Linear Model: The two models, energy storage and consumption, represented with eq. (2) are simulated in Matlab using the functions SS and Isim. Students must include a plot showing how the energy storage element, from the storage subsystem, is being "charged" over time, and another plot that shows how the stored energy is being consumed in the energy consumption subsystem to resolve the problem that was identified.

Linearized Model: Linearization is an approximation of a system's response that contains nonlinearities by using the first-order Taylor Series expansion. Consider that one element of the system, whether from the energy storage or consumption models, has a nonlinear behaviour. Determine the operating point, i.e., a state where the rates of change of the state variables are zero leading to an equilibrium state. Thus, the system is considered to be working around the operating point, e.g., steady state, prior to a dynamic disturbance. Linearize the state and output 
equations (as shown in eq. (1)) around the operating point, as follows,

$$
\begin{aligned}
& \dot{\hat{\boldsymbol{q}}}=\frac{\partial \boldsymbol{f}(\overline{\boldsymbol{q}}, \overline{\boldsymbol{r}}, t)}{\partial \boldsymbol{q}} \widehat{\boldsymbol{q}}+\frac{\partial \boldsymbol{f}(\overline{\boldsymbol{q}}, \overline{\boldsymbol{r}}, t)}{\partial \boldsymbol{r}} \hat{\boldsymbol{r}} \\
& \widehat{\boldsymbol{y}}=\frac{\partial \boldsymbol{h}(\overline{\boldsymbol{q}}, \overline{\boldsymbol{r}}, t)}{\partial \boldsymbol{q}} \widehat{\boldsymbol{q}}+\frac{\partial \boldsymbol{h}(\overline{\boldsymbol{q}}, \overline{\boldsymbol{r}}, t)}{\partial \boldsymbol{r}} \hat{\boldsymbol{r}}
\end{aligned}
$$

recalling that $\boldsymbol{q}$ is the state vector and $\boldsymbol{r}$ is the input vector. The bar operator indicates operating point conditions, and the hat operator indicates the incremental changes around the operating point. Note that eqs. (2) and (3) are equivalent, thus the solution to the differential system of equations is linear. Finally, the overall response of the system is obtained as follows,

$$
\boldsymbol{q}(t)=\overline{\boldsymbol{q}}+\widehat{\boldsymbol{q}}(t) \text { and } \boldsymbol{y}(t)=\overline{\boldsymbol{y}}+\widehat{\boldsymbol{y}}(t)
$$

Nonlinear Model: Simulate the system as modelled using eq. (1), by considering at least two nonlinear terms from either the energy storage or consumption models. For this simulation employ Matlab's function ode45. Here students use Matlab to integrate the nonlinear state equations and compute the resulting output equations.

2.2.4 Design Reflection. In this section, students reflect the performance of their design and how they could improve their design in the future. They also discuss the effects of changing the design parameters of the system during the simulations.

\section{PROJECT MANAGEMENT}

\subsection{Role of Instructor and Teaching Assistants}

Undoubtedly, a project of this kind requires more preparation, guidance, and assistance than traditional scripted projects where all the students work on the same problem. The role of the instructor and teaching assistants (TAs) is to mentor the teams. To keep control of the project, teams of students (generally 3-4 members) are required to submit a proposal with three or four distinctive concepts, and the instructor, in collaboration with the teaching assistants, provides feedback on feasibility and complexity. The goal of the proposal is to identify either very ambitious projects that go beyond the scope of the course or very simple projects that do not meet the expectations of the course. Throughout the term, students receive constant support and guidance.

\subsection{Remote Teaching (2020)}

During the COVID-19 pandemic and the evident uncertainty of assessing students with final exams, it was decided to put more emphasis on the project. The project was delivered as a combination of team and individual components. Students continued to form teams and work together to identify problems in a particular scenario; however, each student had to design and develop the linear model of one solution to a problem in the same location. Later, teams selected one of these solutions and performed the simulations that involved nonlinear terms.

\subsection{Project Assessment}

In general, engineering design projects are evaluated with rubrics. Rubrics define the criteria for assessment, qualities that will be assessed, and identify the levels of performance that students might demonstrate for each quality [9]. The rubrics for the project are in the appendix. For the 2020 remote teaching project, the individual and team components were worth $60 \%$ and $40 \%$, respectively.

\section{STUDENT PROJECTS}

Remote Dwelling (2015). Students identified common problems that occur in an isolated dwelling, such as heating and generation of electricity. Interestingly, there was clear diversity in the way students harvested energy from natural resources, some examples are geothermal, hydro, solar, wind, and wave energy (Fig. 1).

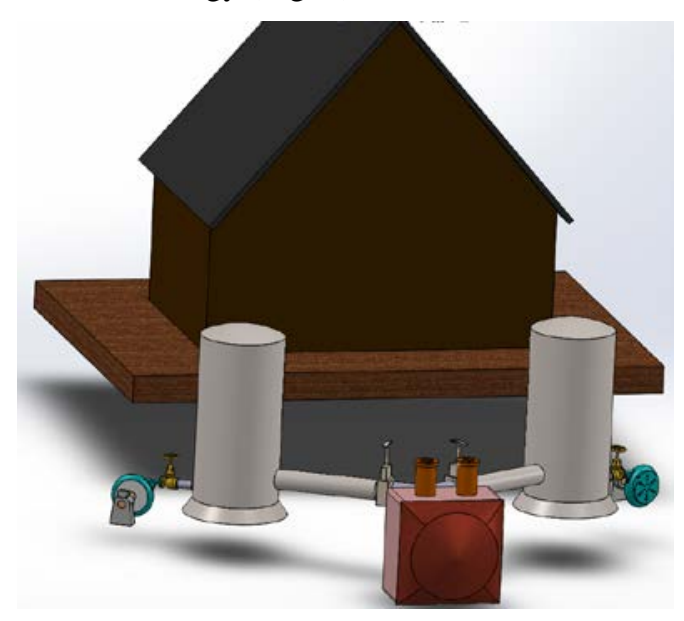

Fig. 1. Electricity generated with wave energy, Tofino, BC. Courtesy of T. Baimukhametov, H. Song, and Y. Wang.

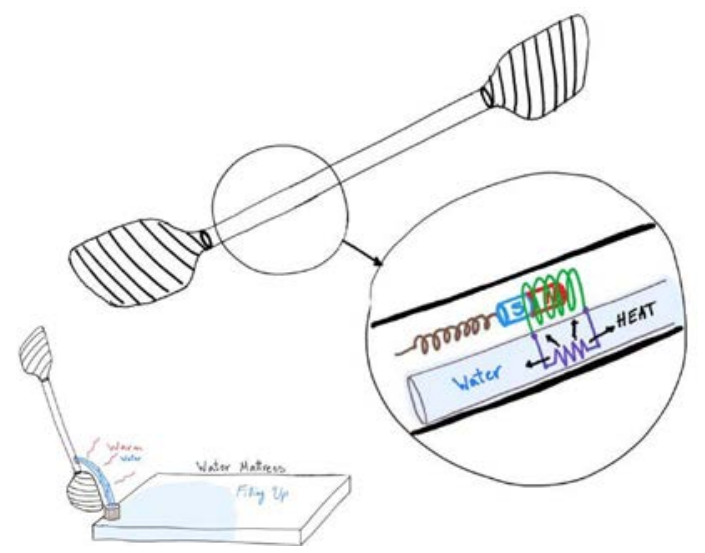

Fig. 2. Heating water mattress with paddles, Garibaldi, BC. Courtesy of L. Page, N. Du, C. Tang, and M. Miri. 
Camping Trip (2017). In this scenario, students recognized more specific problems, such as drying clothes, deter wildlife, rescue systems, cooking, heating devices, among others. Students also acknowledged, that in addition to natural resources, campers perform many outdoor activities where energy could be harvested, such as walking, biking, kayaking, etc. (Figs. 2 and 3).

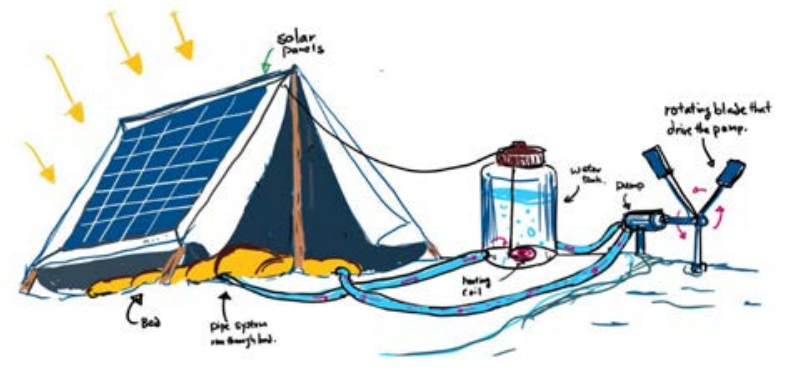

Fig. 3. Heating system with multi-inputs, Vancouver, BC. Courtesy of J. Evans, D. Liu, L. Akkerman, and A. Trainor.

Daily-Life Setting (2018). In this scenario, students also identified several opportunities to harvest energy that is dissipated in large cities. For example, harvesting energy from the gust of air coming through the tunnels of the skytrain, exercise equipment inside gyms, employ the potential energy from people coming down the skytrain

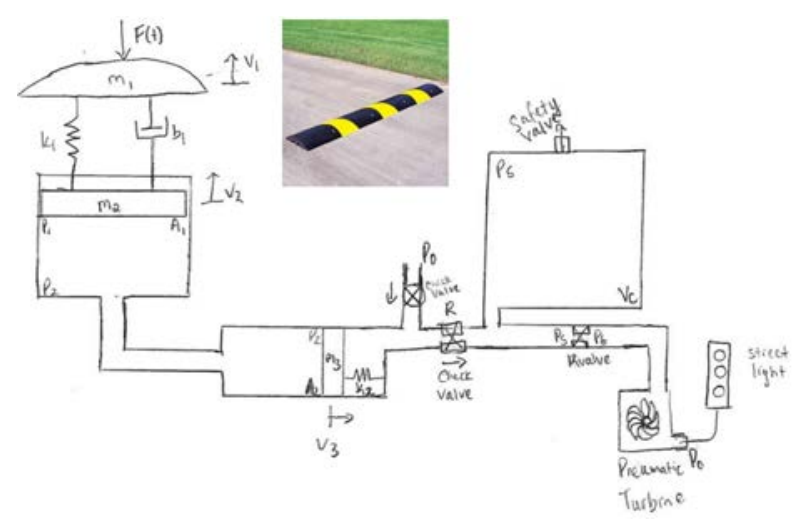

Fig. 4. Construction zone traffic light, Vancouver, BC. Courtesy of J. Dhaliwal, R. Gohalwar, and S. Sohirad.

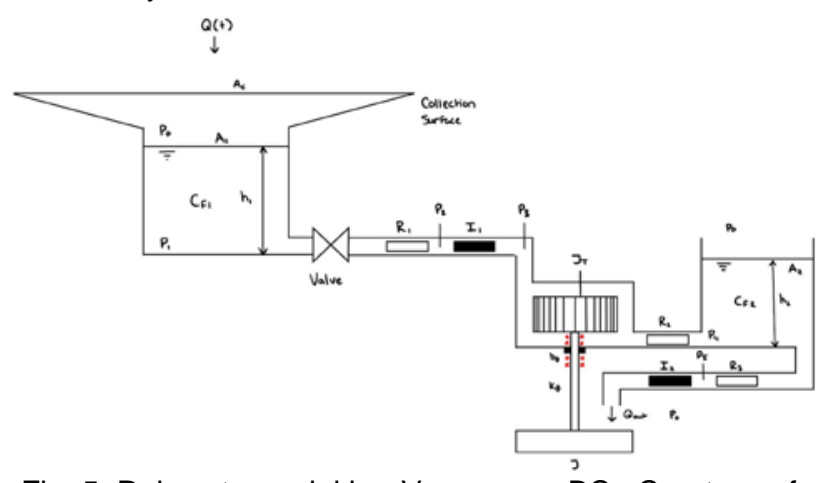

Fig. 5. Rainwater sprinkler, Vancouver, BC. Courtesy of G. Chiu, K. Cheung, E. Cervantes, and C. Jang. using passive escalators to power an elevator for people with disabilities, operating traffic lights in construction zones with flexible bumpers, harvesting energy from piezoelectric floor, among others (Figs. 4 and 5).

Village from Developing Country (2019): In this scenario students investigated problems around the world, for example the discharge of flooded rice fields during monsoon season in South Asia using pumps, irrigation during the drought season in Northern India using stupas (artificial glaciers), uncovering of a Russian village after sandstorm with mechanical shovels, irrigation in SubSaharan Africa using solar uplift towers, controlling freezing temperatures in rural Iran using solar collectors (as opposed to the current practice of burning tires), producing hydroelectricity to power a cooking device in an Amazonian village, among others (Figs. 6 and 7).

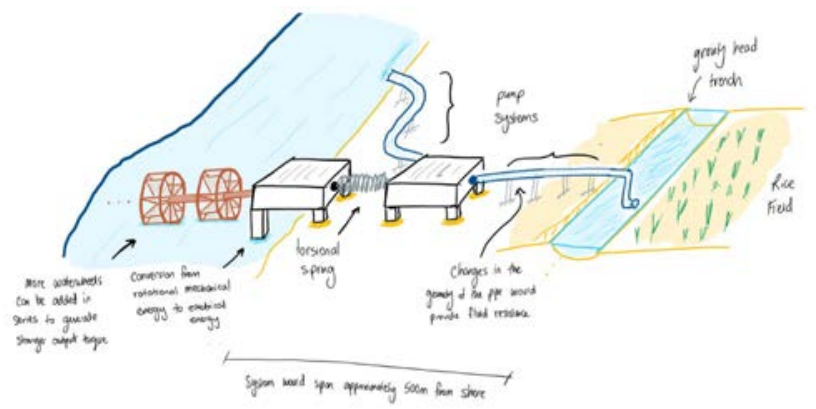

Fig. 6. Discharge of flooded rice fields during Monsoon season, Assam, India. Courtesy of Z. Vajahath, A.

Divinagracia, K.D. Nguyen, and D. Gichuru

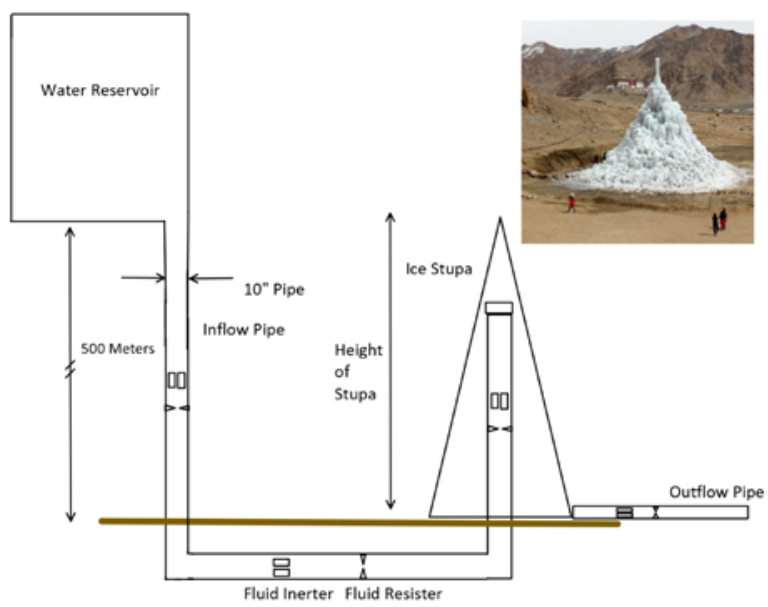

Fig. 7. Irrigation during drought season in Ladakh, India, Courtesy of S. Khan, N. Merali, V. Ojha, and V. Leon.

COVID-19 Infected Location (2020): In this scenario, some students focused on medical devices such as ventilators and sterilizers. Other students considered nonmedical systems that promote social distancing and disinfection of potentially contaminated surfaces in public areas, like shopping malls, gyms, and public bathrooms, or at home. Some examples are disinfecting shopping carts 


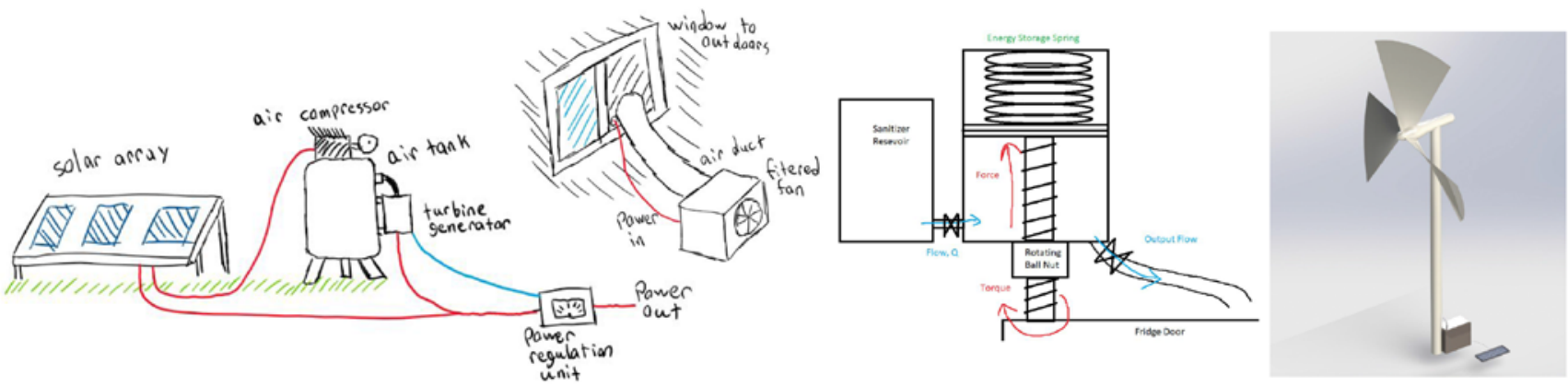

Fig. 8. Three concepts for the kitchen sanitation: ventilation (solar energy), disinfection of fridge handle (mechanical energy from the door), and UV sanitation (wind energy). Courtesy of A. MacDonald, J. Fritsch, and A. Maqsood.

with energy harvested while in use, sanitizing doorknobs and handles, automatic dispensing and delivery systems to avoid human interaction, etc. (Fig. 8).

Shown below in Fig. 9 is an example of the structure of the project. Herein, students identified that in the small village of Shalatne in the region of Maharashtra, India, the water that arrives is pure but scarce. Water is collected hours before its use and is left stagnant for long periods of time during which malaria carrying mosquitoes may infect it with their eggs. Students developed a system to purify the water using an UV system. The team decided to harvest wind energy. Data of the wind conditions of the region were obtained from official tables. The wind turbine was located far from the village, so mechanical energy was converted to electricity with a generator. A long electrical cable carried the electricity and powered a motor that lifted a heavy mass to the top of a mountain (energy storage). When water purification was required, the mass was released down the mountain and a second generator converted the mechanical energy to electricity, which was employed to power the UV system.
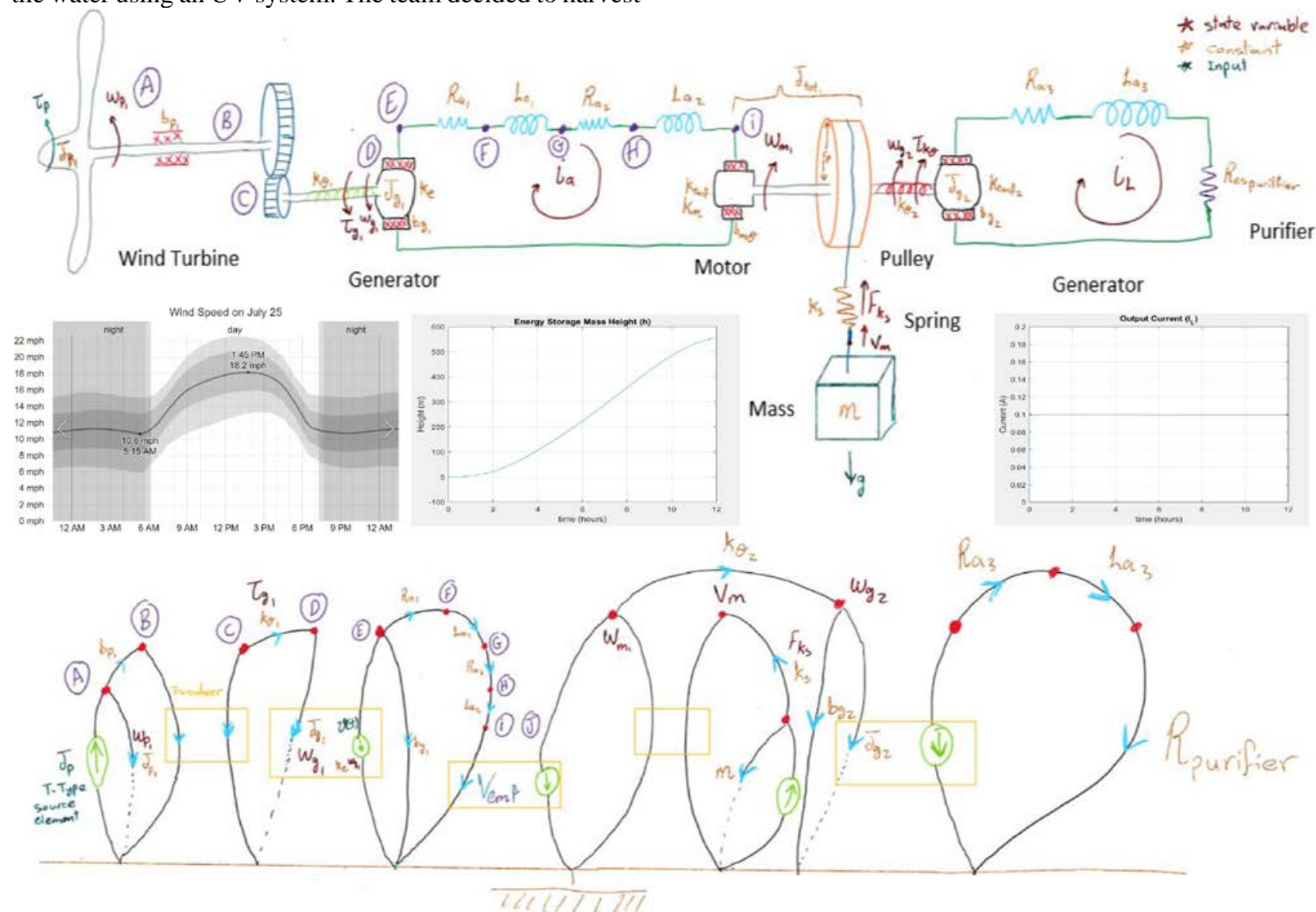

Fig. 9. Water purifier in Shalatne, India. From top to bottom the figure shows: the design of the system, the input data of wind speed in the region, the graphs for energy storage and consumption, and the linear graph of the overall system.

Courtesy of L. Magel, N. Najar, T. Khanchandani, and T. Scott. 


\section{PROJECT EXPERIENCE}

\subsection{Learning Objectives}

The project was conceived to promote several attributes in the mind of young engineer students. These include:

Innovation and creativity: The project is a blank canvas delimited by the scenario, where students have to identify a problem. Students are free to select the location where the system is intended to work. On many occasions, students select a place or a problem that they are familiar with, thus this provides a sense of ownership that engages them to perform better. Students are required to explore different alternatives promoting creativity and innovation.

Resourcefulness: Within a selected location, students must investigate the characteristics of their particular setting and identify how the system will be powered. The system can be powered by using renewable energy or by using energy that is being dissipated or wasted by an external system. Also, students must investigate in the literature the range of values for the design parameters.

Design: This project not only helps to reinforce the learning of the course material, but also promotes engineering design, which is a critical graduate attribute for the Canadian Engineering Accreditation Board.

Critical Thinking: At the end of the project, students must reflect how their project can be further improved. Also, students establish the boundaries of their system through their design, make educated assumptions, and investigate the effect of changing the design parameters.

Engineering Tools: Students employ engineering tools, such as SolidWorks and Matlab, to design and analyze their own designs.

\subsection{Students' Experience}

The following is an excerpt from a team project in 2020 that involved both team and individual components:

This MSE 380 project helped teach us not only the things taught in this course, but also about the engineering design process in general. Prior to this, we had not had the opportunity to design a system as in depth as these. It gave us confidence in our abilities when we realized the types of complex systems that we have the ability to successfully model and simulate. The end result is a piece of work that we are all proud of and can reference in the future. Learning concepts in lecture and solving practice problems only takes your education so far. By designing such problems and solving them with no available "solution", but rather a practical goal in mind cements the concepts discovered in this course on a whole other level. That being said, this is by far the most intense and time consuming project either of us have ever worked on. But for how much we learned about design, modelling and simulation, it was probably worth it.

\subsection{Pedagogical Reflection}

Through this project, students learn the essence of modelling and simulation. Students understand that through simulations one can gain insights of the physical system, analytical models are flexible as they can be quickly and easily modified, experiments are inexpensive, and models can become the basis for control strategies. Also, students recognize the limitations of analytical models such as the errors caused by assumptions, simplifications, and unmodeled factors.

The delivery of the project has evolved over years and will continue to do so. Through this evolution, the quality of the projects has improved considerably. The implementation for future projects is relatively simple, as it only requires establishing a new scenario. This simple change has an important effect on the creative approach. On the one hand, students focused more on natural resources of renewable energy (wind, hydro, solar, etc.) in the scenarios related to the remote dwelling and the underdeveloped village; on the other hand, students opted to investigate more about the interaction of humans or machines with their surroundings in the scenarios related to the daily-life setting and camping, i.e., there was more interest to investigate how to harvest and employ wasted energy.

Our experience aligns with the expectations described in the literature. In general, students are motivated, resourceful, and creative. We also noticed a greater retention of knowledge, which can be supported by the performance of the students on the final exam, that has improved since the first year, from an average of $60 \%$ on the first year to nearly $70 \%$ on subsequent years. However, we also acknowledge that some students are not ready to tackle a project of this kind on their own. This became more evident during the 2020 remote teaching course, where the project combined team and individual components. While some individual students struggled with the project and required more assistance, other students could not complete all the individual components. In the future this project will be re-established as a team project.

\section{CONCLUSIONS}

A design engineering project focussed on sustainability has been implemented for five years in a Systems Modelling and Simulation course offered at SFU. The project is challenging but the students are engaged and eager to tackle a real problem that they identify. The project has succeeded our expectations. Students are creative and resourceful. We believe that through this project, students not only reinforce the learning material of the course, but also makes them feel proud for confronting a real engineering problem. 


\section{References}

[1] Clarence de Silva, Modeling and Control of Engineering Systems, Taylor \& Francis, 2009, 796 pp \{ISBN: 978-142007686-8\}

[2] Sonia M. Gómez Puente, S. M, Michiel van Eijck, and Wim Jochems, "Towards Characterising Design-Based Learning in Engineering Education: A Review of the Literature," European Journal of Engineering Education, vol. 36, no. 2, pp. 137-149, 2011

[3] Kolmos, A., \& De Graaff, E. Problem-Based and ProjectBased Learning in Engineering Education. In A. Johri and B. Olds (Eds.), Cambridge Handbook of Engineering Education Research (pp. 141-160). Cambridge: Cambridge University Press., 2015.

[4] Sonia M. Gómez Puente, Corinne Jongeneelen, and Jacob Perrenet, Design-Based Learning in Mechanical Engineering. In Campos et al. (Eds.) Project Approaches to Learning in Engineering Education: The Practice of Teamwork (pp. 89-108). SensePublishers, 2012.

[5] Benoit Galand, Benoit Raucent, and Mariane Frenay, "Engineering students-self-regulation, study strategies, and motivational believes in traditional and problem-based curricula," International Journal of Engineering Education, vol. 26, no. 3, pp. 523-534, 2010.

[6] Filip Dochy, Mien Segers, Piet van den Bossche, and David Gijbels, "Effects of Problem-Based Learning: A MetaAnalysis," Learning and Instruction, vol, 13, pp. 533-568, 2003.

[7] Denis Bédard, Christelle Lison, Daniel Dalle, Daniel Côté, and Noël Boutin, "Predictors of Student's Engagement and Persistence in an Innovative PBL Curriculum: Application for Engineering Education,” International Journal of Engineering Education, vol. 26, no. 3, pp. 511-522, 2010.

[8] Flavio Firmani, Sohad Kadhum S., and Peter Wild, "Expanding Engineering Design with Mini Projects - Theory of Mechanisms a Pilot Course," in Proceedings of the Canadian Engineering Education Association (CEEA), (Canmore, AB: June 8-11), 7 pages, 2014.

[9] Bazylak J. and Wild P., "Evaluation System for Capstone Engineering Design Reports," in Proceedings of the Canadian Engineering Education Association (CEEA), (Kingston, ON: June 7-9), 8 pp., 2010.

\section{Appendix: Assessment Rubric}

\begin{tabular}{|c|c|c|c|c|c|c|c|}
\hline & Topic & Unacceptable (0) & Marginal (1) & Satisfactory (2) & Commendable (2.5) & Exceptional (3) & Weight \\
\hline \multirow{5}{*}{ 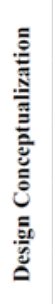 } & Design Objectives & No valid objectives & At least one valid objective & One justified valid objective & $\begin{array}{l}\text { Two valid objectives and } \\
\text { somehow justified }\end{array}$ & Two justified design objectives & 0.5 \\
\hline & Original Design & - & Reproduction (copy) & Same concept as other teams & $\begin{array}{l}\text { Some subsystems similar to other } \\
\text { teams }\end{array}$ & Unique, original & 1.5 \\
\hline & Alternative Concepts & No valid concepts & One valid concept & Two valid concepts & Three valid concepts & $\begin{array}{l}\text { Three valid concepts (one } \\
\text { exceptional) }\end{array}$ & 1 \\
\hline & $\begin{array}{l}\text { Selection of Concept } \\
\text { Design }\end{array}$ & No decision is made & Decision is not justified. & $\begin{array}{l}\text { Decision is justified but is not } \\
\text { objective. }\end{array}$ & $\begin{array}{l}\text { Decision is justified and somehow } \\
\text { objective }\end{array}$ & $\begin{array}{l}\text { Decision is well justified and } \\
\text { objective }\end{array}$ & 0.5 \\
\hline & Design Complexity & $\cdot$ & Incomplete System & Basic design. & $\begin{array}{l}\text { Complex design in at least one } \\
\text { subsystem }\end{array}$ & $\begin{array}{l}\text { Complex design in at least two } \\
\text { subsystems }\end{array}$ & 1 \\
\hline \multirow{5}{*}{ 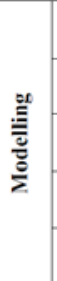 } & Input Variable & No Data & Limited Data and no reference & Limited Data with reference & $\begin{array}{l}\text { Acceptable and interpolated data } \\
\text { with reference }\end{array}$ & $\begin{array}{l}\text { Exceptional and interpolated } \\
\text { data with reference }\end{array}$ & 1.5 \\
\hline & Element Modelling & Incomplete Model & Basic Model & Satisfactory Model & Commendable Model & Exceptional Model & 2 \\
\hline & System Modelling & Incomplete Model & Basic Model & Satisfactory Model & Commendable Model & Exceptional Model & 3 \\
\hline & Linear Graph & Missing Model & Incomplete Model & Satisfactory Model & Commendable Model & Exceptional Model & 3 \\
\hline & Design Parameters & No parameters & Unrealistic parameters & $\begin{array}{l}\text { Realistic but unjustified } \\
\text { parameters }\end{array}$ & Realistic parameters and justified & $\begin{array}{l}\text { Realistic and justified initial } \\
\text { parameters, and refined }\end{array}$ & 1.5 \\
\hline \multirow{4}{*}{ 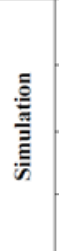 } & $\begin{array}{c}\text { Linear Model } \\
\text { (Energy Storage) }\end{array}$ & No analysis & Incomplete analysis & Erroneous analysis & $\begin{array}{l}\text { Complete analysis with basic } \\
\text { discussion }\end{array}$ & $\begin{array}{l}\text { Complete analysis with proper } \\
\text { discussion }\end{array}$ & 2.5 \\
\hline & $\begin{array}{l}\text { Linear Model } \\
\text { (Consumption) }\end{array}$ & No analysis & Incomplete analysis & Erroneous analysis & $\begin{array}{l}\text { Complete analysis with basic } \\
\text { discussion }\end{array}$ & $\begin{array}{l}\text { Complete analysis with proper } \\
\text { discussion }\end{array}$ & 2.5 \\
\hline & Linearization Model & No analysis & Incomplete analysis & Erroneous analysis & $\begin{array}{l}\text { Complete analysis with basic } \\
\text { discussion }\end{array}$ & $\begin{array}{l}\text { Complete analysis with proper } \\
\text { discussion }\end{array}$ & 3 \\
\hline & Nonlinear Model & No analysis & Incomplete analysis & Erroneous analysis & $\begin{array}{l}\text { Complete analysis with basic } \\
\text { discussion }\end{array}$ & $\begin{array}{l}\text { Complete analysis with proper } \\
\text { discussion }\end{array}$ & 3 \\
\hline \multirow{4}{*}{ 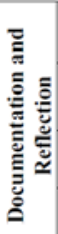 } & Design Reflection & No reflection & $\begin{array}{l}\text { Marginal and unsupported } \\
\text { reflection }\end{array}$ & $\begin{array}{l}\text { Acceptable reflection that is in } \\
\text { some way supported }\end{array}$ & $\begin{array}{l}\text { Acceptable and supported } \\
\text { reflection }\end{array}$ & $\begin{array}{l}\text { Insightful and soundly supported } \\
\text { reflection }\end{array}$ & 1.5 \\
\hline & $\begin{array}{c}\text { Computer-Aided } \\
\text { Design and Sketches }\end{array}$ & $\begin{array}{l}\text { No Drawings (CAD and } \\
\text { sketches) }\end{array}$ & Incomplete Drawings & $\begin{array}{l}\text { Drawings that somehow } \\
\text { supported the design process }\end{array}$ & $\begin{array}{l}\text { Acceptable drawings that } \\
\text { supported the design process }\end{array}$ & $\begin{array}{l}\text { Exceptional drawings that } \\
\text { supported the design process }\end{array}$ & 1 \\
\hline & References & None & Incomplete & Acceptable & Commendable & Exceptional & 1 \\
\hline & Other Documentation & $\begin{array}{l}\text { Missing Documentation } \\
\text { (Abst, Intrd., Concl., Codes) }\end{array}$ & $\begin{array}{l}\text { Incomplete Documentation } \\
\text { (Abst, Intrd., Concl., Codes) }\end{array}$ & $\begin{array}{l}\text { Acceptable Documentation } \\
\text { (Abst. Intrd., ConcL., Codes) }\end{array}$ & $\begin{array}{l}\text { Commendable Documentation } \\
\text { (Abst, Intrd. Concl., Codes) }\end{array}$ & $\begin{array}{l}\text { Exceptional Documentation } \\
\text { (Abst, Intrd., Concl., Codes) }\end{array}$ & 1.5 \\
\hline & & & & & & & 31.5 \\
\hline
\end{tabular}

The terms exceptional, commendable, satisfactory, etc. are defined relative to the expectations of the project. Proposal is worth 5 pts. Half a point will be given for presentation, yielding to a maximum total of $3 \times 31.5+5+0.5=100 \mathrm{pts}$. 